\title{
SAFETY MANAGEMENT IN CONSTRUCTION PROJECTS
}

\author{
YOUSIF S. SAEED \\ Dept. of Civil Engineering, University of Kirkuk-Iraq
}

\begin{abstract}
The aim of this research is to identify and evaluate the safety management in construction projects to minimise and control health and safety $(H \& S)$ of construction workers. Questionnaire is used to collect a wide range of opinions from experienced professionals working in different construction sites for comparison between them. The reviews of the related literature are the first step in obtaining information from previously related studies.

The literature reviews provide a theoretical background about safety management that guided the design of the questionnaire. This research concludes that the construction industry has a high number of fatalities and long-term injuries. This is unacceptable in a modern society and it also makes the industry inefficient, with days lost due to injuries. This research shows that the high rates of accidents are due to several common factors, such as poor construction planning, lack of safety in design, inadequate safety training, worker behaviour, inherent safety H\&S risk of construction and lack of knowledge of site rules.
\end{abstract}

KEY WORDS: H\&S risk management, Construction project, Health and Safety (H\&S), Employee/Worker, Accident, Injury, Questionnaire.

\subsection{INTRODUCTION}

Tafety management is essential knowledge in a project management area which recognized in The Guide to the Project Management Body of Knowledge (PMBOK Guide, cited by Cretu et al., 2011). Safety management is expected to take account of all risks and accidents that may possibly be expected that put project employees at risk. The health and safety $(\mathrm{H} \& \mathrm{~S})$ of any workplace is very important to diminish such risks, legally and ethically, but in mainly dangerous contexts such as the construction industry HS takes on perilous importance as daily activities of the industry are highly unsafe. It is thus important to identify suitable safety activities and strategy, accommodating potential serious H\&S pr`oblems (Twort and Rees, 2011).

Past research in the area show clearly that construction projects create frequent possible threats to the lives of employees, and serious injuries and mortalities are frequent in the construction industry. Thus, the consideration and management of safety, along with consideration to $\mathrm{H} \& \mathrm{~S}$ generally, is undeniably fundamental to any construction project. By proper $H \& S$ planning many of the myriad $H \& S$ risks in construction can be prevented.

Accordingly, accidents on the construction sites are principally attributable to hazardous human behavior (i.e. individual factors) and/or unsafe working conditions (i.e. system factors). Moreover, it is obvious that there is a serious problem with falls, which problem is common throughout the global construction industry.

Safety management is the procedure used to recognize H\&S risks and implement actions to decrease the possibility of a risk materializing and to diminish or eliminate the potential consequences of identified project H\&S risks. This research focused on principle type of risks in construction projects: risk of construction on health and safety (H\&S) of employees.

Injuries and fatalities resulted in accidents in the construction industry still an obstacle clings construction industry to its infamous position as the industrial sector responsible for more occupation accidents, than any other. Consequently, the improvement of $\mathrm{H} \& \mathrm{~S}$ in construction is still an essential goal for all contributors in the construction processes. Safety management is likely to take account of all risks and accidents that may believably be expected that put project employees at risk, to minimize such risks. It is thus important to identify appropriate safety actions and strategies to accommodate potential serious H\&S problems.

Therefore, the aim of the research is to identify and evaluate the safety management in construction projects to diminish and control risk to H\&S of employees/workers. This aim could be achieved by:

Analysing the H\&S problems related to the construction industry and explore solutions to avoid risk on life of construction crews.

- Understanding side effects of construction processes on the H\&S of employees to reduce the site accidents and injuries. 


\subsection{ACCIDENTS}

Accidents are defined as "an undesired event that results in physical harm to people or damage to property" (Peyton and Rubio, 1991, 162). Accidents could occur during construction and destruction activities, resulting in injury, mostly incurred by workers on the work site. Accidents might occur during site investigation and survey of a project, project items implementation. Figure 1 displays the percentage terms of the causes of fatal injuries in the UK construction industry during 1997-2003. Almost half of all fatalities were due to falls from height, according to this pie chart, approximately a third fatalities struck by a moving vehicles and objects. Other fatalities were subjected to electricity accidents, collapse accidents, and other (Howarth and Watson, 2009).

\section{Causes of fatalities in the UK construction industry 1996-2003}

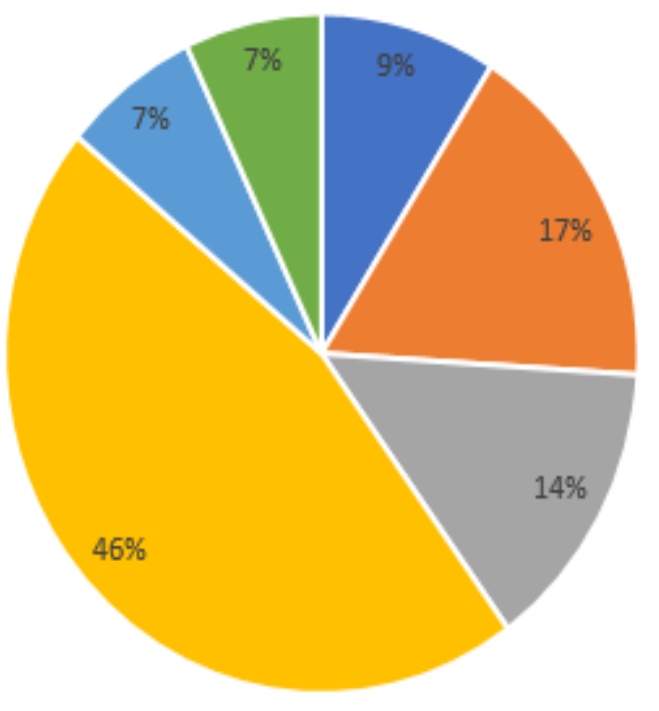

- Other

- Struck by a moving object

- Struck by a moving vehicle

- Fall from height

- Trapped by something collapsing/overturning

- Contact with electricity

Fig. (1): Causes of fatalities in the UK construction industry 1996-2003 (adapted from: Howarth and Watson (2009))

\subsection{CAUSES OF CONSTRUCTION ACCIDENTS}

Unsafe work site conditions were main reason of arising $10 \%$ of accidents on the construction site arise as Schaufelberger and Lin (2014) stated, and $90 \%$ were resulted in unsafe behavior. Likewise, the HSE declared that about $80 \%$ of accidents in the UK are due to human behavior (cited by Li and Poon, 2013). Furthermore, Peyton and Rubio (1991) acknowledged that work accidents in sites occur through two main mechanisms: unsafe conditions and unsafe acts. In addition, unsafe behavior may arise due to a worker's state of mind, tiredness, stress, or physical condition (Schaufelberger and Lin, 2014). Also, many factors such as insufficient and poor communication, sub-contracting to negligent firms, lack of H\&S training and low educational level of construction staff members leads to accidents as affirmed by Cheng et al. (2004). Schaufelberger and Lin (2014) recognized some examples of accident causes, such as:

A worker notices a dangerous condition but he/she does not do anything to correct it (e.g. use of defective equipment such as a ladder).

An individual performing the work in faulty way or unsafe manner due to lack proper training.

A worker may disregard the safety conditions then an accident may occur.

Lehto and Salvendy (1991) stated three main models of accidents causation namely: "(1) generic accident process models; (2) error of human and dangerous behavior models; and (3) human lesions mechanism models". 


\subsubsection{Falls accidents and injuries}

Janicak, 1998 stated that construction employees are a high-risk population for falls from height. Derr et al. (2001) identified that the number of fatal accidents has increased because of falls on the construction site in different subsectors. Also, in the US most accidents are falls from height (Huang and Hinze, 2003; Schaufelberger and Lin, 2014). In addition, in the UK the highest rate of injures is that of falls
(Table 1) (HSE, 2013c). Furthermore, many fall from height accidents in the Spain construction industry, consisting half of all work-related accidents that in the Spain as underlined by Rubio-Romero et al. (2013). They reported that about $40 \%$ of fatal accidents occur due to falls from structures. Moreover, about $30 \%$ of these are falls from temporary devices on structures assembled to labor at height (i.e. scaffolding).

Table (1): The main causes of worker's fatalities in the UK (Source: HSE (2013c))

\begin{tabular}{lccc}
\hline \multirow{2}{*}{\begin{tabular}{l} 
Injury kind \\
\cline { 2 - 4 }
\end{tabular}} & $\begin{array}{c}\text { Construction } \\
2012 / 13 \mathrm{p}\end{array}$ & \multicolumn{2}{c}{ Proportion of fatalities in } \\
\cline { 2 - 4 } & $59 \%$ & $49 \%$ & All industries \\
\hline Falls & $3 \%$ & $10 \%$ & $25 \%$ \\
\hline Being struck by falling/moving object & $5 \%$ & $11 \%$ & $16 \%$ \\
\hline A collapse/overturn & $10 \%$ & $10 \%$ & $10 \%$ \\
\hline Being hit by a moving vehicle & $5 \%$ & $7 \%$ & $4 \%$ \\
\hline Electricity & & & $15 \%$ \\
\hline
\end{tabular}

According to the HSE (2013b), the number of fatal injures has generally decreased, but the percentage of fatal injuries caused by falls has not reduced over the last decade in the UK (Figure 2).

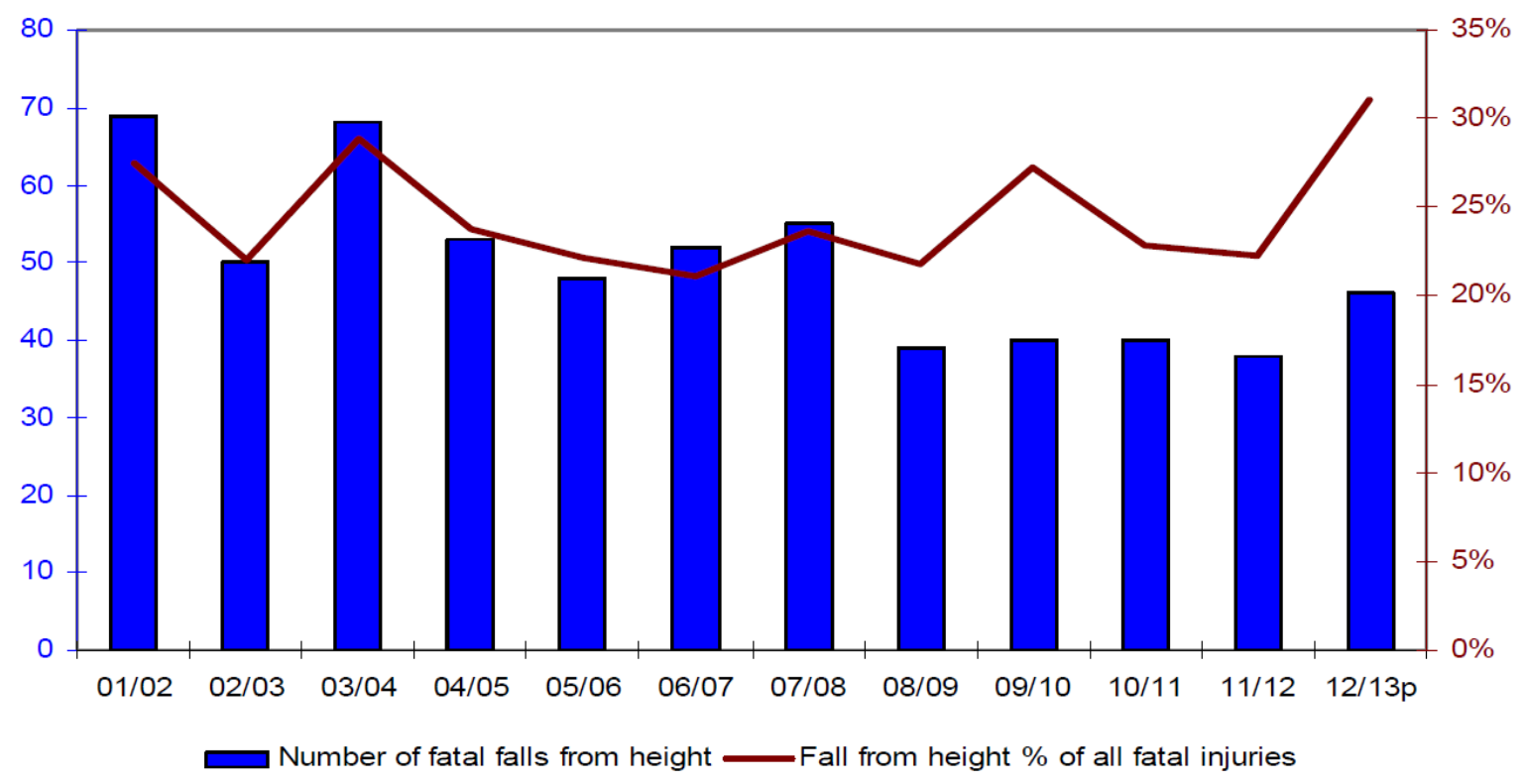

Figure Error! No text of specified style in document.: UK work-related fatal injuries due to fall from height, 2001-2013 (Source: HSE (2013b))

According to Griffith and Howarth, 2001, the main causes of fatal accidents during the erection and dismantling of scaffolding are due to platforms lacking edge protection. Therefore, more investigations of scaffolding are demanding to minimize and control the height number of accidents were due to unsafe scaffolding RubioRomero et al. (2013).

Accordingly, the findings of this study, some recommendation could be produced that are necessary for safer scaffolding OHSAS (2016):

Hire an outside scaffold erector AS/NZS (2001). 
Ensure that a capable person should be trained on the scaffold location with at least on course of OSHA (2012) scaffold user.

An appropriate scaffolding frame should be considered for the task BS OHSAS (2009).

Figure 3 shows a breakdown of this category of fatal accidents. Bobick et al. (1994) proposed two types of falls protection on construction sites to prevent workers from falling and to avoid the falling of materials and objects: primary fall protection, such as planks and crawling boards; and secondary fall protection to minimize the impact of falls after they occur, such as safety nets and lifebelts. Griffith and Howarth (2001) established that the second most prolific cause of fatal accidents was falling materials and objects.

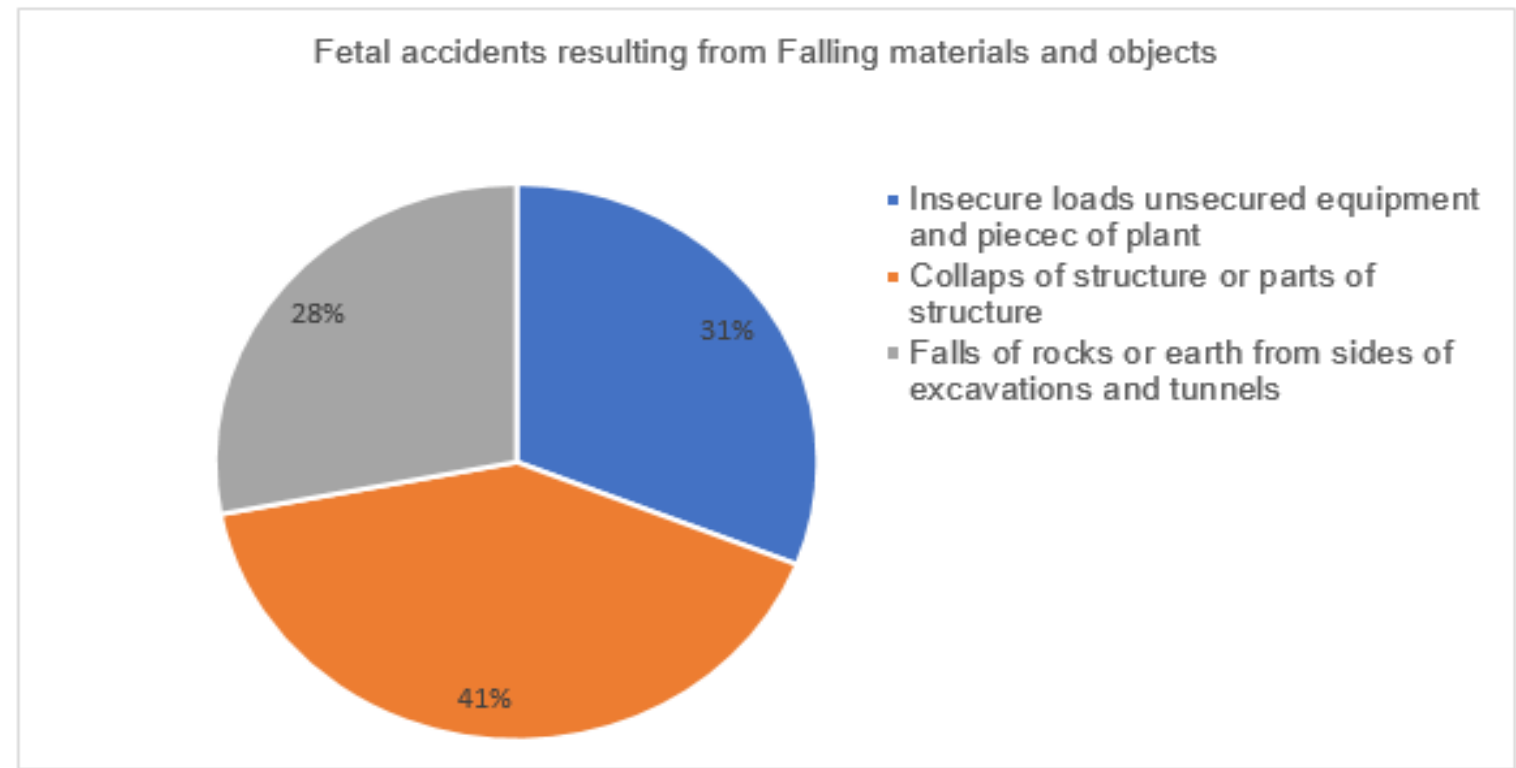

Fig. (3): Fatal accidents resulting from falling materials and objects (Source: HSE (1988, cited by Griffith and Howarth,2001))

\subsection{PROTECTIVE CLOTHING AND SAFETY EQUIPMENT}

To reduce the risk of on sites accidents, protective clothing wearing and the use of personal protective equipment is very essential. The employers must (by law) provide safety equipment and protective clothing for all employees, Likewise, Employees have a duty to protect their own H\&S (Davies and Tomasin, 1990). Additionally, employees on the construction site must (by law) supervised by a qualified $H \& S$ supervisor to ensure that the employees follow the safety instruction to wear protective clothing to keep worker's safer (Zin and Ismail :2012).

\subsubsection{Standards of personal protective equipment}

Davies and Tomasin (1990) highlighted that the protective clothing should be chosen according to the effect of its material to resist penetration, the ability of its design and the condition of environment in which it should be worn. Joyston-
Bechal and Grice (2004) reported that employers must ensure that they provide suitable clothing/equipment for the employees, and safety clothing must be appropriate for the $\mathrm{H} \& \mathrm{~S}$ risks involved.

Davies and Tomasin (1990) claimed that in providing protective clothing and safety equipment, employers should:

Identify hazards before starting any construction work.

Inform and consult with employees.

Remove hazards where possible.

Provide instruction and training on how to use equipment.

\subsection{COMPULSORY PROTECTIVE CLOTHING AND EQUIPMENT}

Davies and Tomasin (1990) pointed out that in the UK, every employer must (by law) provide:

Sufficient and preferable protective clothing and equipment for employees (Construction (Health and Welfare) Regulation, 1966). 
Protective clothing and protective breathing equipment for the workers where dust presents in the atmosphere (Asbestos Regulations, 1969).

Insulation boots and special gloves for electricians (Electricity Regulations, 1944).

Safety belt, lines etc. (Construction (Working Places) Regulation, 1966).

Ear protectors (Noise at Work Regulation, 1989).
Safety helmets (Construction (Head Protection) Regulation, 1989).

Tam et al. (2004) showed that the only personal protection equipment universally provided to workers on construction sites by employers in China are eye goggles, gloves and hard hats (helmet); however, many workers are dissatisfied with such provisions, and they believe that these items of protective clothing are insufficient to protect them (Figure 4).

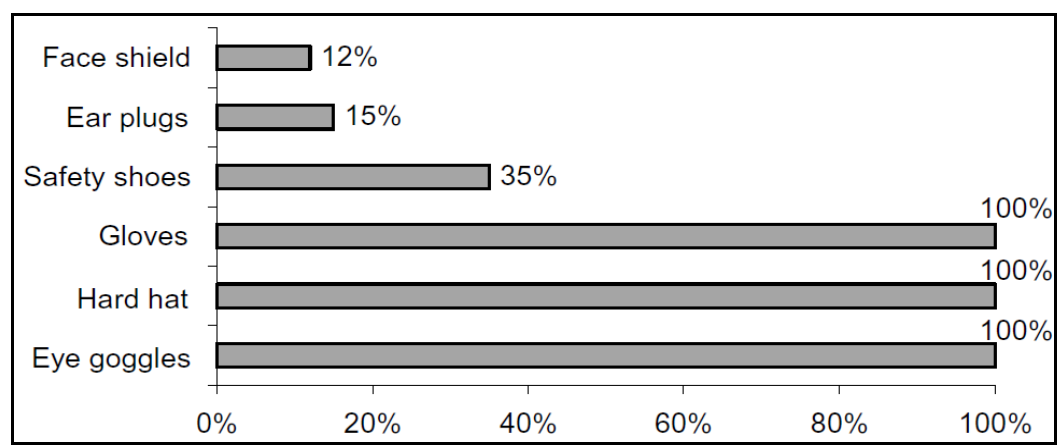

Fig. (4): Personal protective equipment provided by contractors in China (Source: Tam et al. (2004))

\subsection{RESEARCH METHODOLOGY}

A structured questionnaire was used for the first part of this research. The aim of the questionnaire was to collect a wide range of opinions from the experience professional people working in different construction sites and make comparison between them. The survey questionnaire was developed and distributed to various stakeholders Establish the aims and objectives of the project.

(designers, project managers, site engineers, Determine the sample.

contractors, clients, and others) involved in Choose survey methodology.

construction projects.

Create the questionnaire.

To understand and analyze the best strategies and Pre-test the questionnaire, if practical.

issues about safety management in construction Conduct the survey.

projects, structured questionnaire tool for research methodology were used

\subsection{QUESTIONNAIRE}

To collect information the designed questionnaire sent to construction-related professionals as a list of questions. A large size of information (usually quantitative) collected from people quickly, this could be mentioned as the main advantage of the questionnaire. Through the questionnaire, the mind of professional people about issues can be developed and analyzed. The responses were not instantaneous; respondents could answer freely when they had time and were not afraid to express their honest views.
Analyse the data.

The questionnaire should be short, simple and unambiguous as possible to get highest rate of response. To allow wider range of responses the survey format was designed to be simple to complete, with many of the questions being of multiple choice, significant/insignificant, agree/disagree, and yes/no. The survey completely comprised of eleven questions divided in two sections. The first section was five questions about the background of participants, the second was six questions about safety management.

\subsubsection{Respondents' country}

The United Kingdom and Iraq are two countries where the questionnaire has done, Common problems in both countries focused on in 
the questionnaire, thus it was sent to experts from mentioned countries.

The proportions of respondents by country were:

$33 \%$ from Iraq.

$67 \%$ from the UK.

\subsection{RESULTS ANALYSIS}

The results of the questionnaire and the key points arising from analysis of the results would be presented in this section. About one-third $(33 \%)$ of the respondents were from Iraq. Just over two-third $(67 \%)$ of the respondents are from the UK.

\subsubsection{Background of respondents}

It is obvious that the quality of the data collected by a questionnaire survey is highly dependent on the experience and knowledge of the respondents. These questions were therefore involved to ensure that the respondents were suitable qualified to take part in the survey.

respondents (54\%) worked for contractors, fifteen $(17 \%)$ worked for consultants, eleven (14\%) worked in higher education, ten $(11 \%)$ worked for clients and three (4\%) worked for other administrations such as educational and humanitarian (governmental) directorates (Figure $5)$.

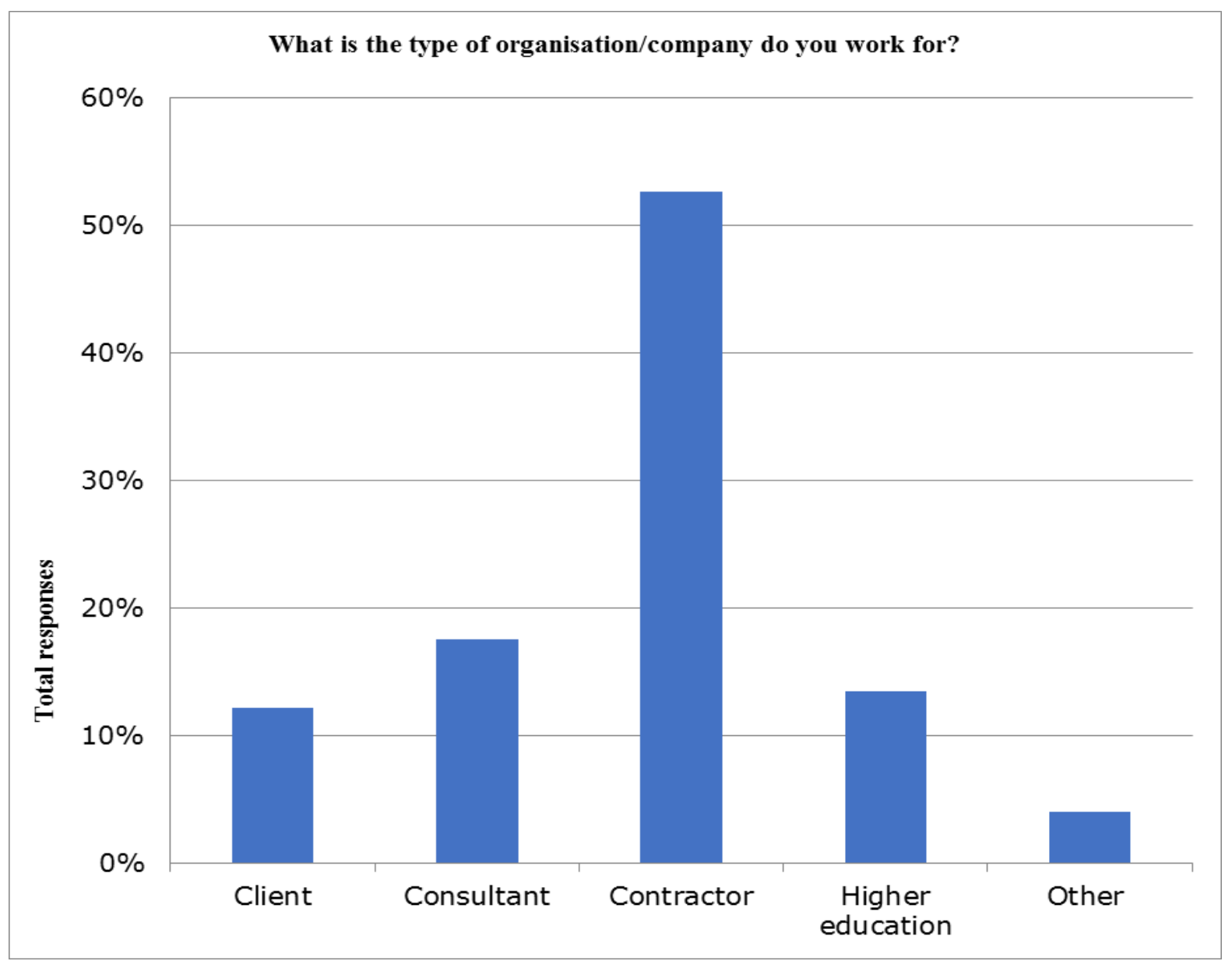

Fig. (5): Respondents' type of organisation

When the survey asked about their roles within the organizations, more than half of the respondents $(58 \%)$ stated they were site engineers,
$18 \%$ were project managers, $12 \%$ were designers and the rest were principal designer 5\% and others $7 \%$ were construction team leader (Figure 6). 


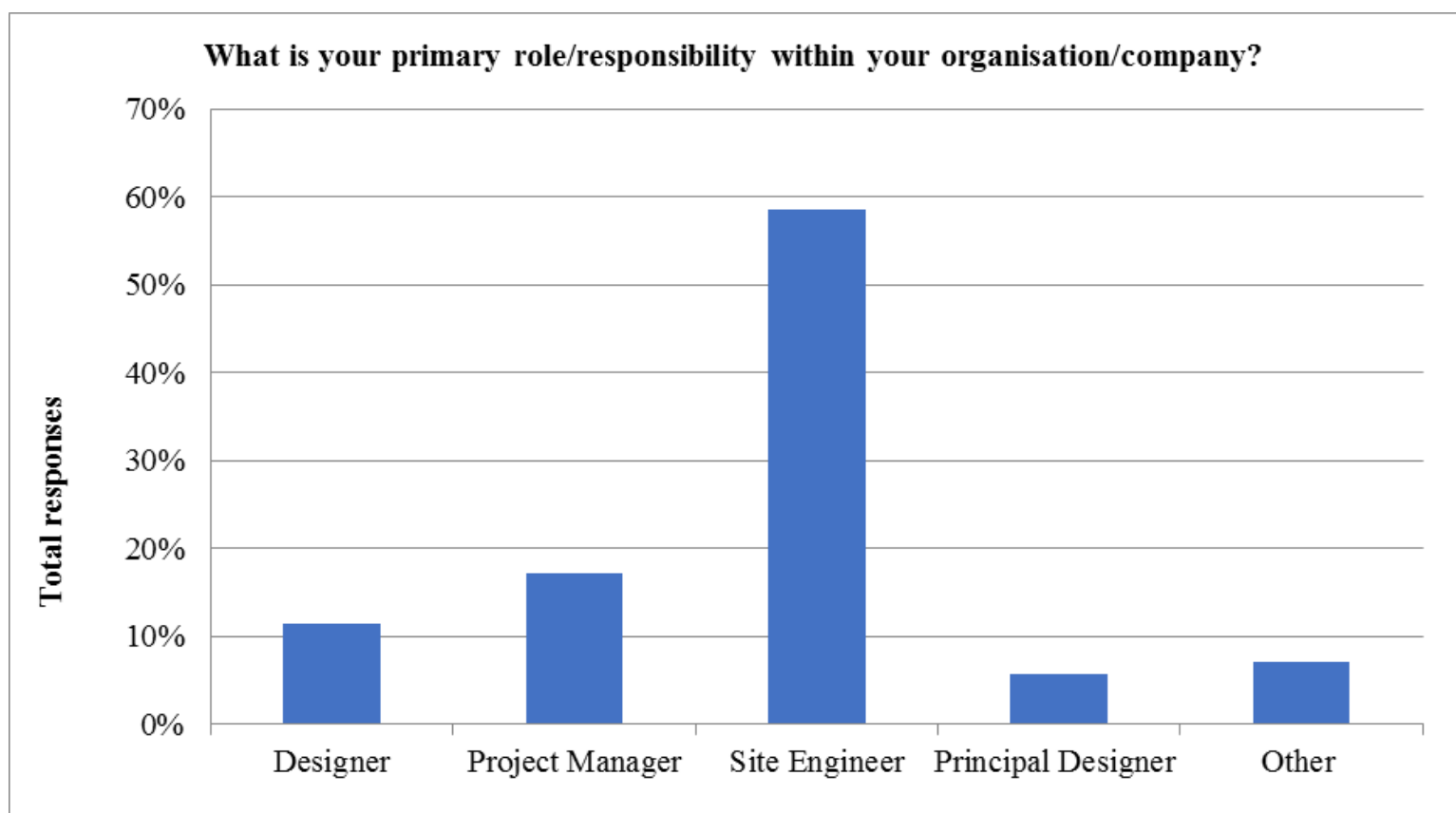

Fig. (6): Respondents' role within organisation

Figure 7 shows the years of experience of the respondents. The largest group (42\%) had 5-10 years of experience, followed by $23 \%$ with $1-5$ years, $21 \%$ with $10-15$ years, $8 \%$ with $15-20$ years and $6 \%$ with more than 20 years of experience. The results from Figure 7 approve that the respondents have widespread ranges of experience and it can be determined that they all have adequate knowledge to take part in this research.

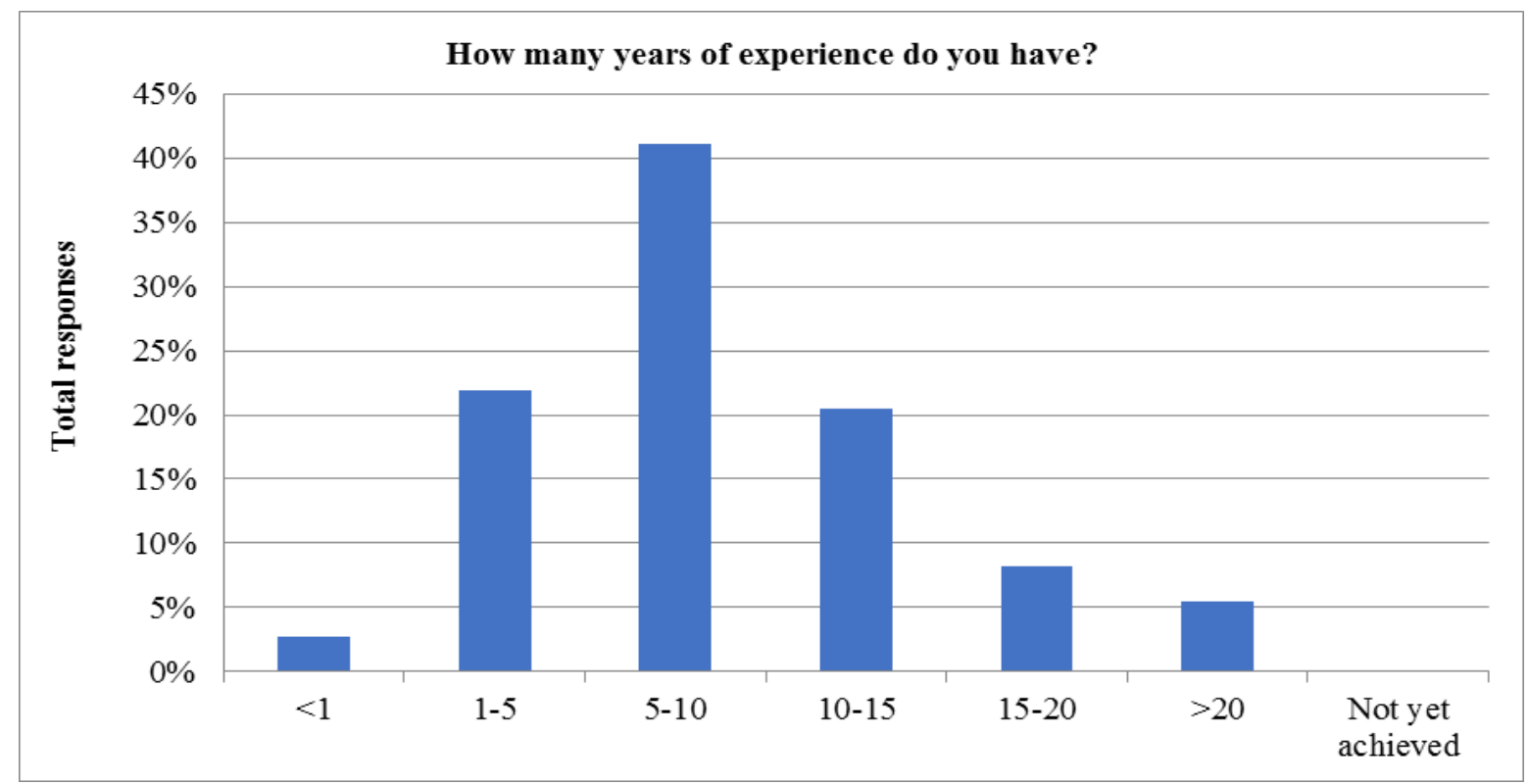

Fig. (7): Experience of respondents

Figure 8 presents fourth survey questions respondents answers, when they asked about their levels of understanding of safety management in construction projects. Results show that most the respondents $(55 \%)$ showed that they understand well, $24 \%$ of respondents indicated they understand very well, and $18 \%$ were familiar with the concept, while just $3 \%$ of respondents were unfamiliar with it (Figure 8). Thus, wide ranges of understanding of safety management participated in this questionnaire which could add more to this research. 


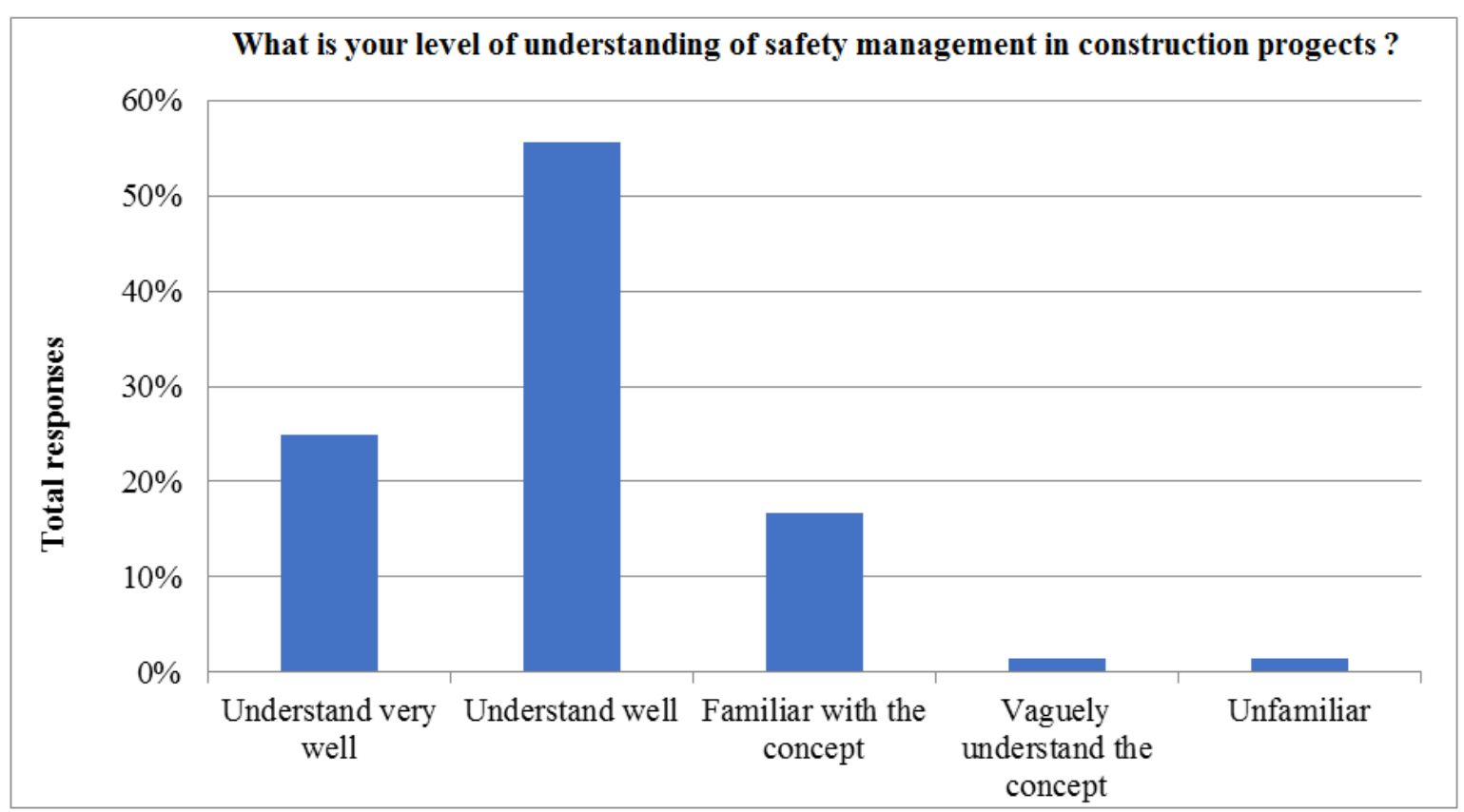

Fig. (8): Respondents' understanding of safety management

\subsection{CONSTRUCTION PARTIES' ROLE IN HEALTH AND SAFETY}

The percentages of respondents working in organizations involved $\mathrm{H} \& \mathrm{~S}$ care on-site illustrated in Figure 9. Giving to the results a huge percentage of organizations $(81 \%)$ involve $\mathrm{H} \& \mathrm{~S}$ care on sites, while only $19 \%$ of organizations did not involve $\mathrm{H} \& \mathrm{~S}$ care on sites (all negative respondents were from Iraq).

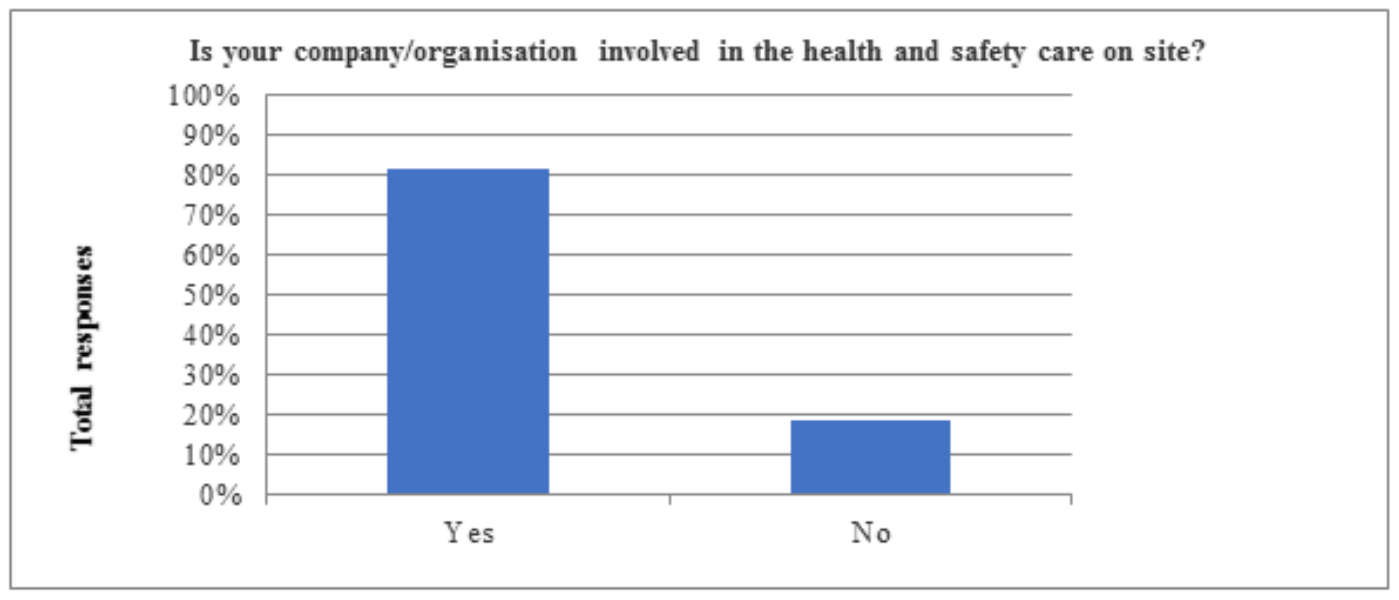

Fig. (9): Organisations' care about H\&S on sites

The H\&S risk of construction processes to the lives and wellbeing of workers could be minimized significantly with the well practicing role of all construction parties of construction processes, but it is essential to find out which parties have the key role in minimizing this $H \& S$ risk. Figure 10 shows that most of the respondents (41\%) believed that contractor has a core role, more than quarter $(27 \%)$ indicated the project manager, and $10 \%$ of respondents indicated the principal designer.

Accordingly, in minimizing constructionrelated H\&S risks to employees, the contractor and project manager have the key roles. The H\&S problems in the construction industries may be produced because of lack of awareness of safety 
problems among construction parties such as contractors and project managers, stated by Tam et al. (2004).

It is obvious that a good relationship between the construction parties on the same site is significant in minimizing $\mathrm{H} \& \mathrm{~S}$ risk, principally between contractors and designers to ensure a safe design and construction. H\&S standards in design significantly would upgraded by minimizing communication gaps between these two parties.

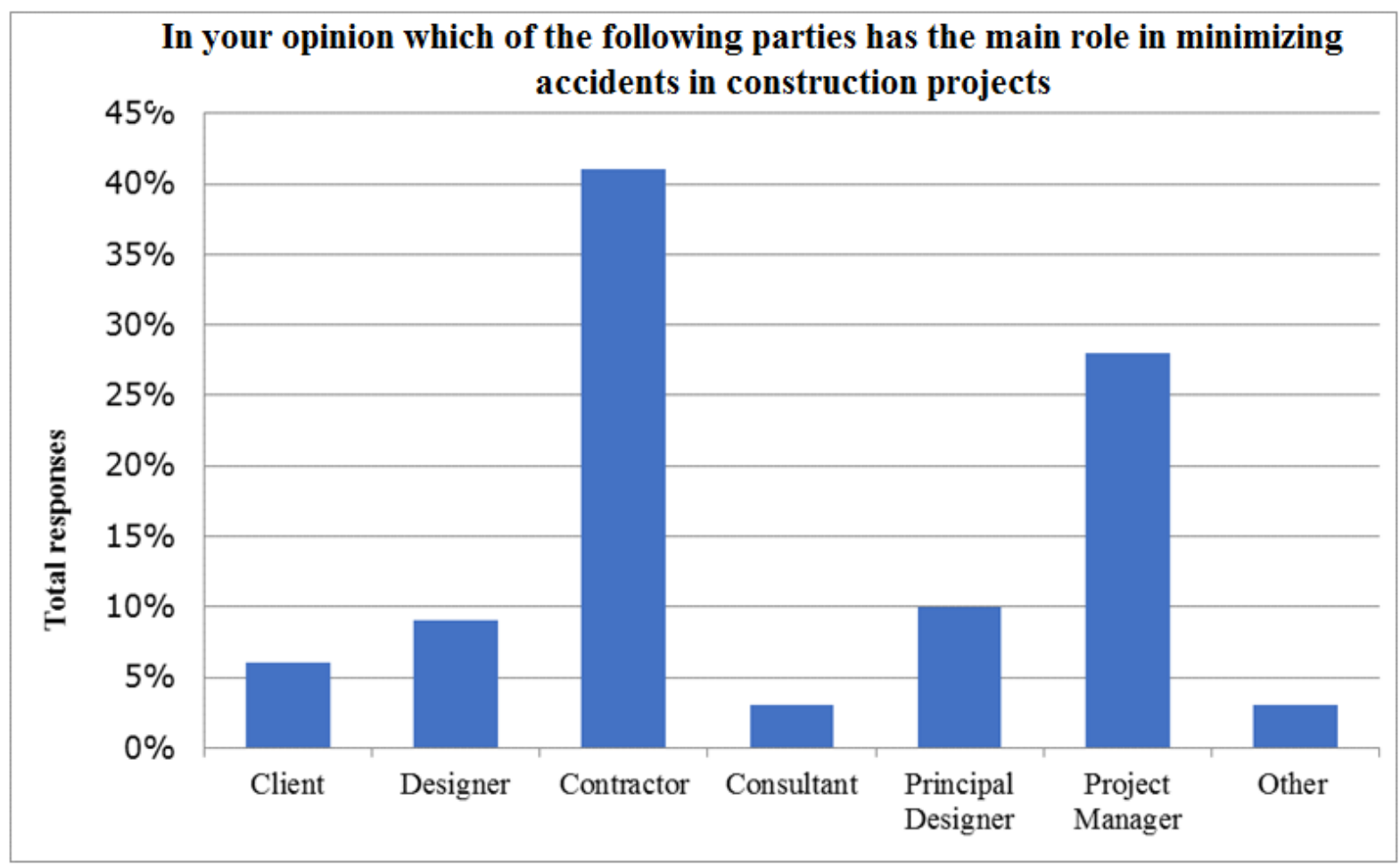

Fig. (10): Respondents' opinions about role of construction parties in minimizing accidents

\subsection{ACCIDENTS AND INJURIES}

Fatal, major and lost working time injuries are three main kinds of any Construction accidents and injuries. Three questions were enquired about these three types of injuries in this survey.

Most the respondents (58\%) believed that falling from height is most likely to cause fatal injuries to workers, $19 \%$ of respondents cited contact with machinery and $12 \%$ of respondents mentioned being struck by a falling/moving object. A small proportion of respondents $(2 \%)$ cited lifting and handling injuries (Figure 11). The HSE (2014c) identified falling from height as the major single cause of construction worker fatalities in the UK in 2013/2014 (Table 2). 


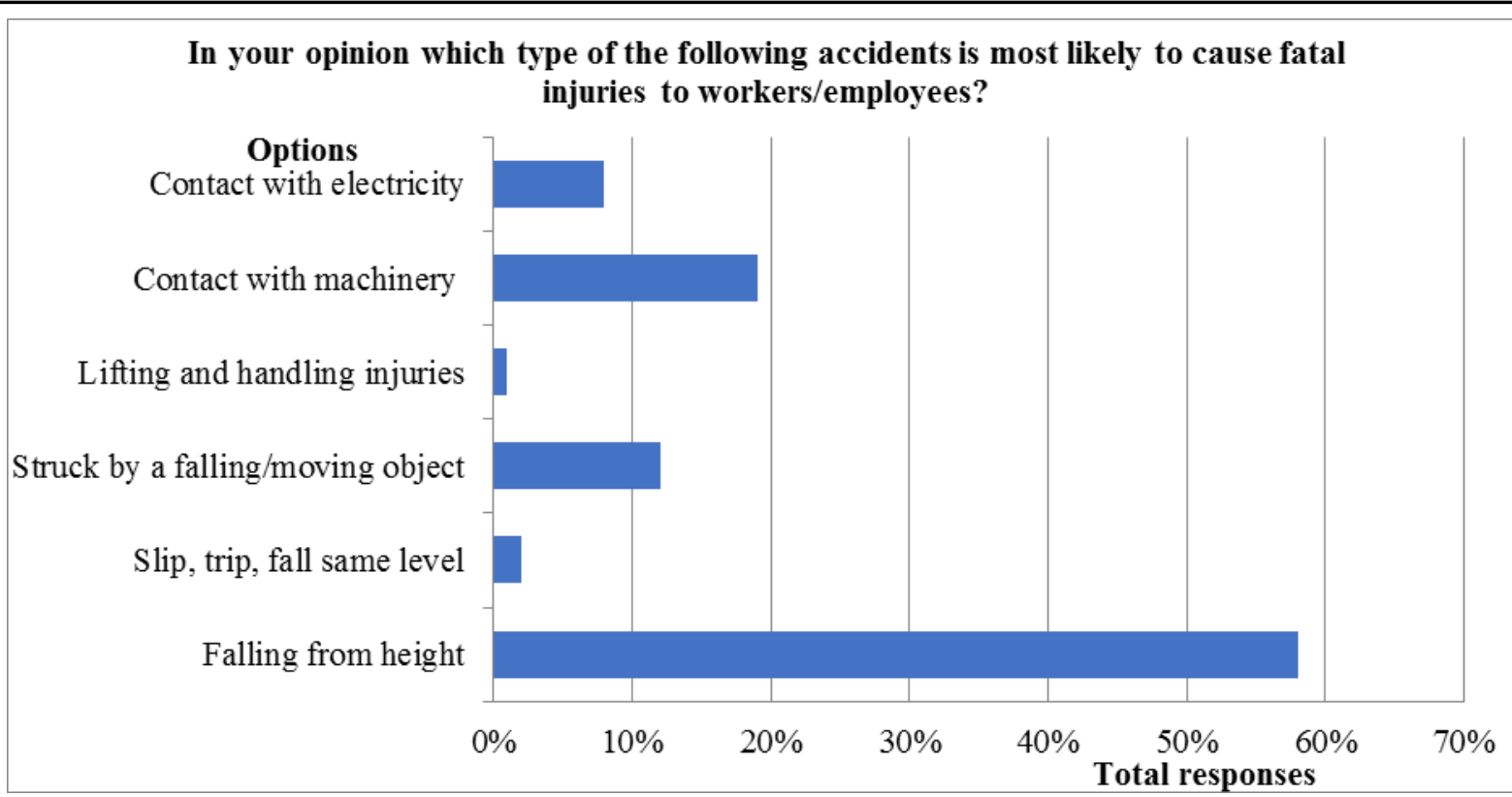

Fig. (11): Respondents' opinions about fatal injuries

Table (2): Kinds of fatal injury in UK construction (Source: HSE (2014c))

\begin{tabular}{lcc}
\hline Kind of Injury & Fatal injuries 2013/14 p & \% of total fatal injuries to workers in construction \\
\hline Fall from height & 19 & $45 \%$ \\
\hline Contact with machinery & 3 & $7 \%$ \\
\hline Struck by object & 3 & $7 \%$ \\
\hline Struck by moving vehicle & 3 & $7 \%$ \\
\hline Contact with electricity & 3 & $7 \%$ \\
\hline Struck against & 1 & $2 \%$ \\
\hline Slip, trip, fall same level & 1 & $2 \%$ \\
\hline $\begin{array}{l}\text { Trapped by something } \\
\text { collapsing }\end{array}$ & 1 & $2 \%$ \\
\hline
\end{tabular}

Figure 12 illustrates six common types of accidents that cause major injuries; the results clearly show that falling from height on one hand and slip, trip and fall on the other have about similar levels of H\&S risk according to most respondents, with $36 \%$ and $32 \%$ respectively. Additionally, $15 \%$ of respondents thought that contact with machinery is the core factor to occur major injuries, $11 \%$ of respondents indicated struck by a falling object. 


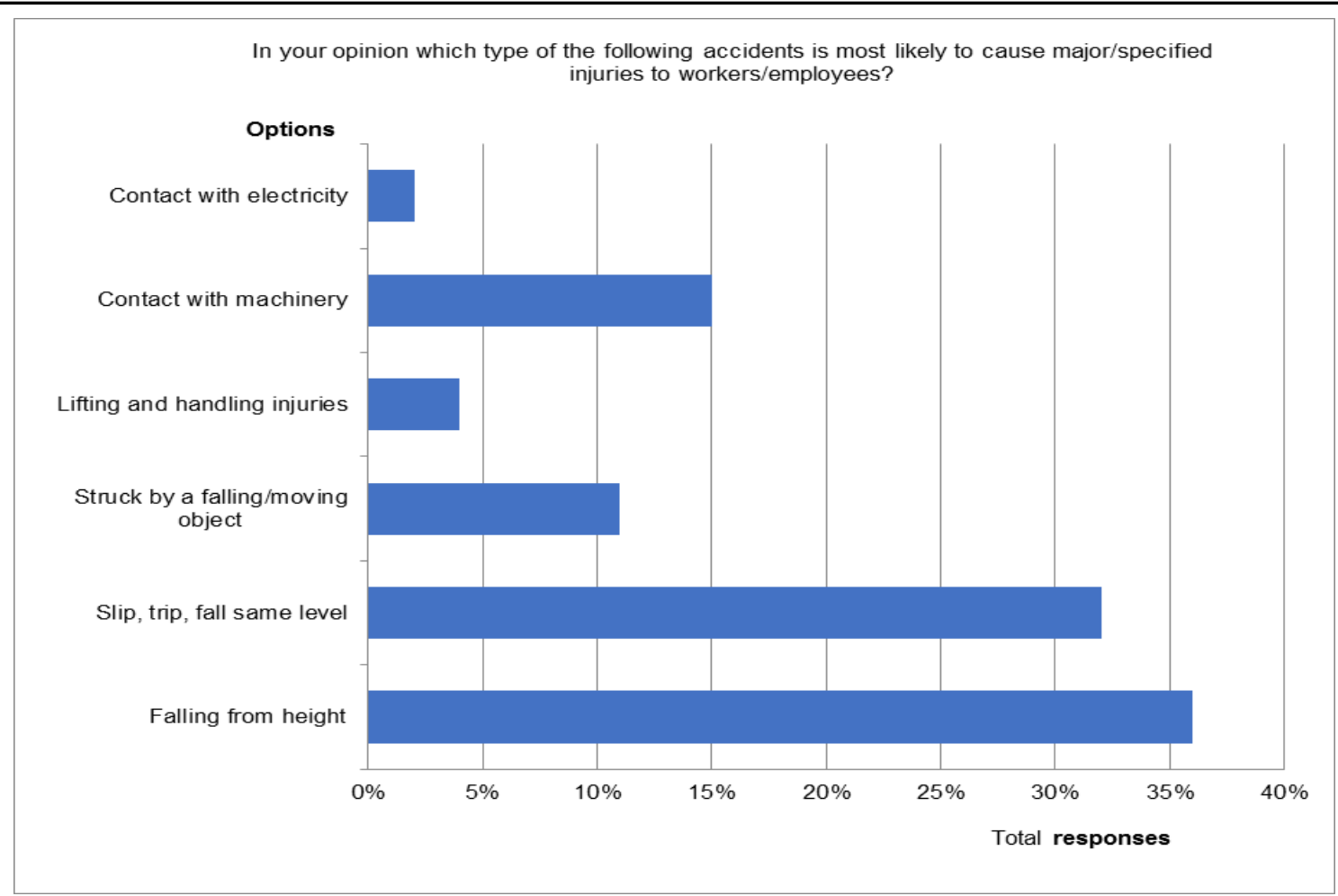

Fig. (12): Respondents' opinions about major injuries

The most likely accident to cause fatal and major injuries to workers in the construction industry is falling from height. During accidents, fatal injuries could be minimized (and mitigated to lost working time injuries) by decreasing falling from height. This decrease could be achieved through using of secure edge protection, safe access, and an appropriate scaffold with good edge protection. Moreover, an effective way to protect workers from falling from high places is using safety belts.

A large proportion of respondents $(39 \%)$ is lifting and handling injures according to the results demonstrated in Figure 13, therefore, lost working time injuries is most likely to occur due to this, and slip, trip, fall same level is the second largest proportion

(30\%). 


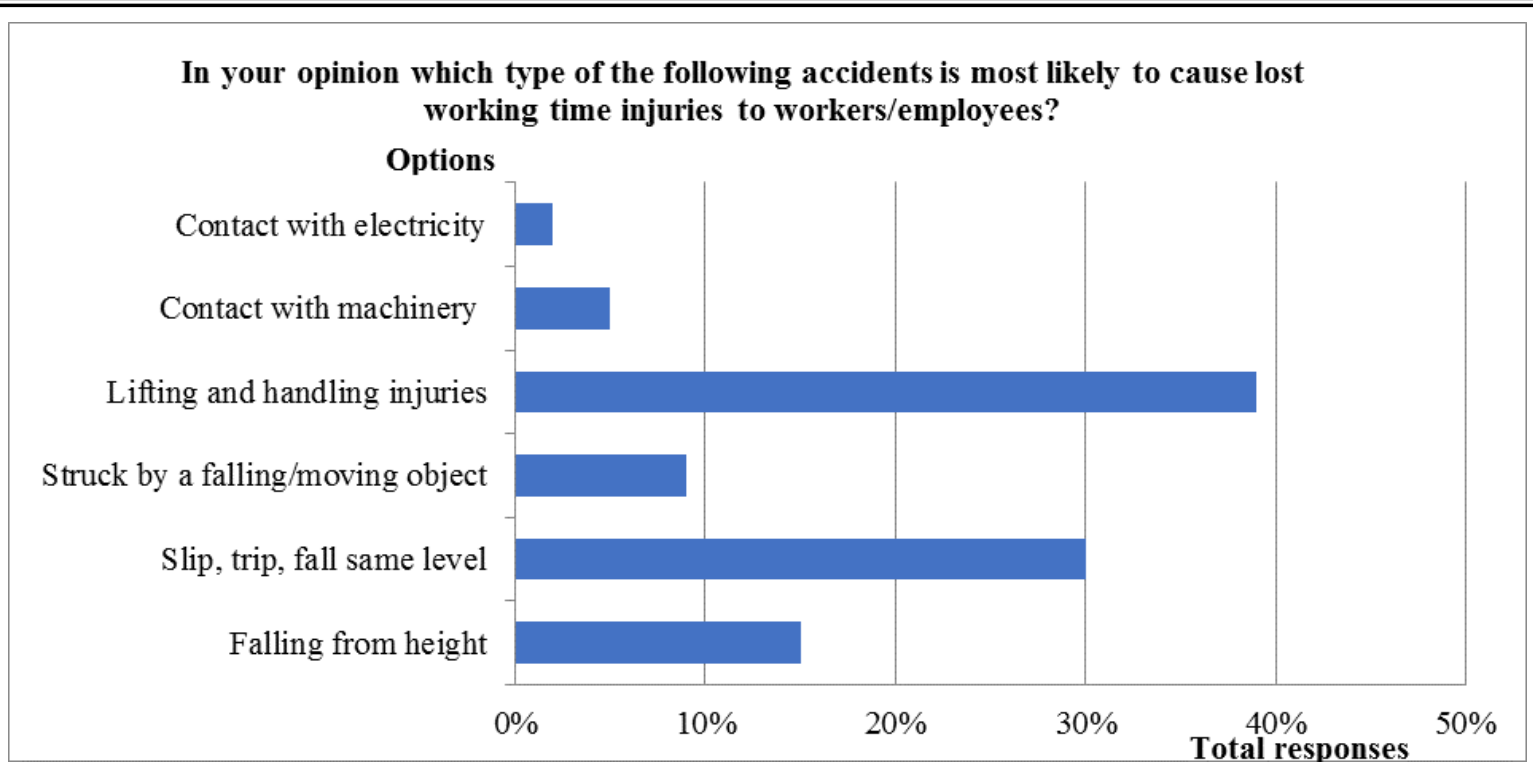

Fig. (13): Respondents' opinions about lost working time injuries

Table 3 illustrates that the maximum rate of special machines/ tools can be used instead of lost working time injures in UK construction in 2013/2014 was recorded (30\%) for lifting and handling injures (HSE 2014C). This type of injuries are the most likely accidents to cause lost working time injuries. To decrease such injuries, manual handling by workers. Likewise, using good conditions and personal protective equipment, according to the type of work could reduce lost working time injuries.

Table (3): Kinds of over-seven-day injury in UK construction (Source: HSE (2014c))

\begin{tabular}{lcc}
\hline $\begin{array}{l}\text { Kind of Injury to } \\
\text { employees }\end{array}$ & Over-7-days injuries 2013/14 p & $\begin{array}{c}\text { Percentage of over-7-day Injuries in } \\
\text { construction }\end{array}$ \\
\hline Lifting and handling injuries & 992 & $30 \%$ \\
\hline Slip, Trip, Fall same level & 681 & $21 \%$ \\
\hline Fall from height & 373 & $11 \%$ \\
\hline Struck by object & 364 & $11 \%$ \\
\hline
\end{tabular}

Accordingly, major H\&S risks to construction teams could be due to all above types of accidents, so administrations must emphasize these types of accidents, especially falls from height, to reduce construction $\mathrm{H} \& \mathrm{~S}$ risks.

Figure 14 illustrate in detail the respondents answer to one of the survey questions asked to show how strongly they agree or disagree with some factors which cause accidents and injuries on sites. generally, most respondents believed all the options cause high rates of accidents and injuries. More than half of respondents (58\%) strongly agreed with high accident rate due to inadequate safety training. 55\% of respondents agreed with high accident rate due to poor construction planning, 55\% of respondents agreed with lack of collaborative working and $49 \%$ of respondents agreed with lack of safety in design. Also, more than half of the respondents (54\%) agreed with high rates of accidents due to worker behavior and $48 \%$ of respondents agreed with high rates of accidents due to non-wearing of personal protective equipment. 33\% of respondents agreed with high rates of accidents due to focused on time and cost of projects rather than safety and $30 \%$ of respondents agreed with lack of knowledge of site rules. In addition, half of respondents (53\%) were neutral about the use of mobile phones, and $40 \%$ of respondents disagreed with high accident rate due to smoking on site. However, just a small majority of respondents strongly disagreed with some options, the largest majority of which was $3 \%$ for smoking on site. 


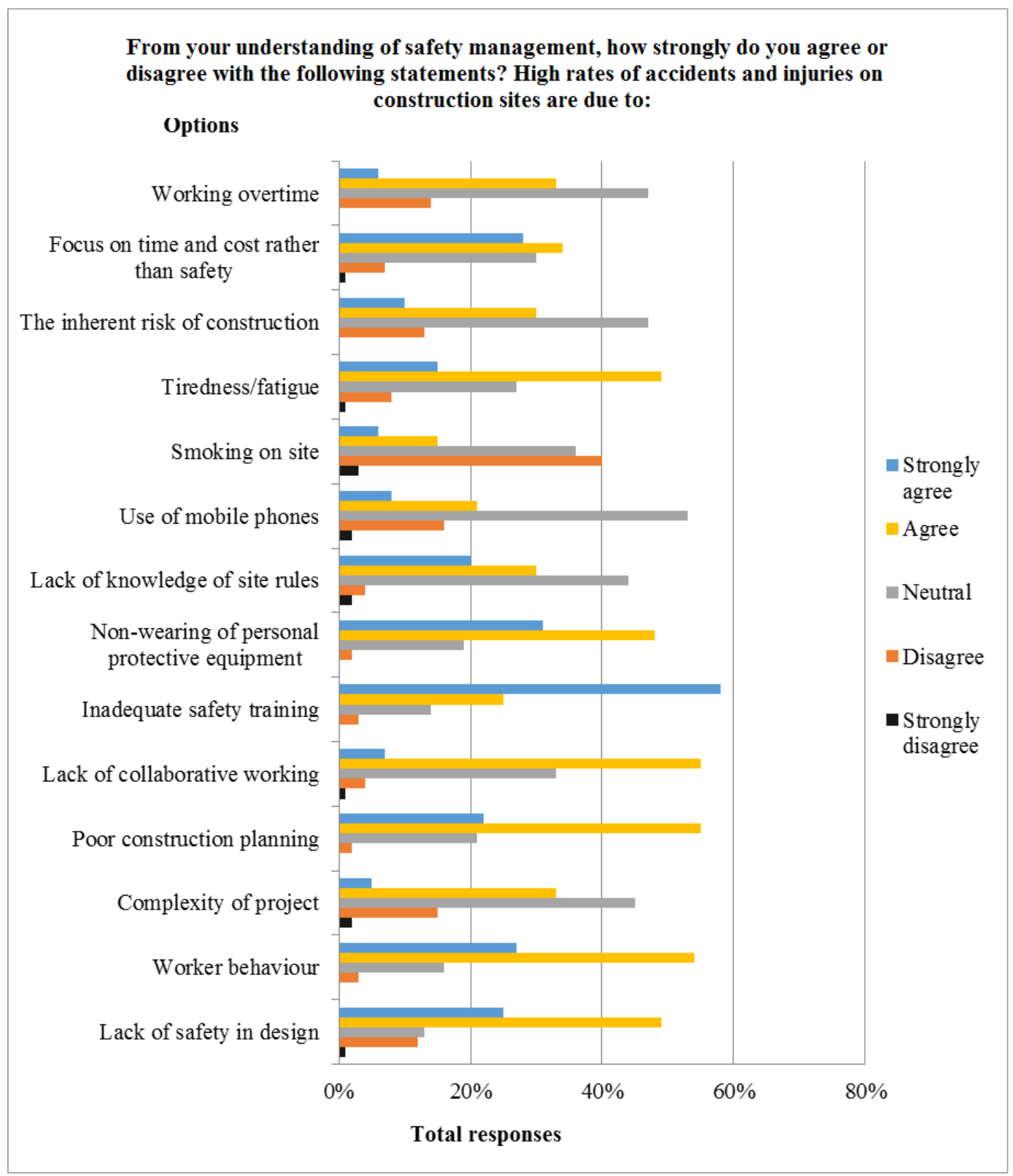

Fig. (14): Respondents' positions about high rates of accidents and injuries

The HSE in the United Kingdom declared that approximately $80 \%$ of accidents are attributable to human behavior (cited by Li and Poon, 2013). Cheng et al. (2004) stated that low educational level of construction staff members is a factor that leads to accidents such as lack of training, insufficient and poor communication error and sub-contracting to negligent firms. Thorpe (2005) and Twort and Rees (2011) suggested that employers should prepare employees before starting construction work and provide relevant information to identify $H \& S$ risks to avert risks to their $\mathrm{H} \& \mathrm{~S}$. Moreover, awareness on the part of contractors is essential to encourage workers to follow $\mathrm{H} \& \mathrm{~S}$ instructions.

Organizations can reduce $\mathrm{H} \& \mathrm{~S}$ risks by providing worker supervisors for each team/group of workers working in different places within projects, especially in large projects. The worker supervisors should have sufficient experience and knowledge to encourage the workers to carry out their tasks safely. 


\section{$1.11 \mathrm{H \& S}$ AND DIFFICULTIES IN CONSTRUCTION PROCESSES}

To reduce risk of construction on workers' lives, thought that $H \& S$ training courses for employees are very significant cited by more than half of respondents (66\%) as shown in Figure 15. Additionally, $59 \%$ of respondents believed that greater penalties for poor $H \& S$ practice are significant, $40 \%$ of respondents believed that more emphasis on H\&S during the planning phase is very important.

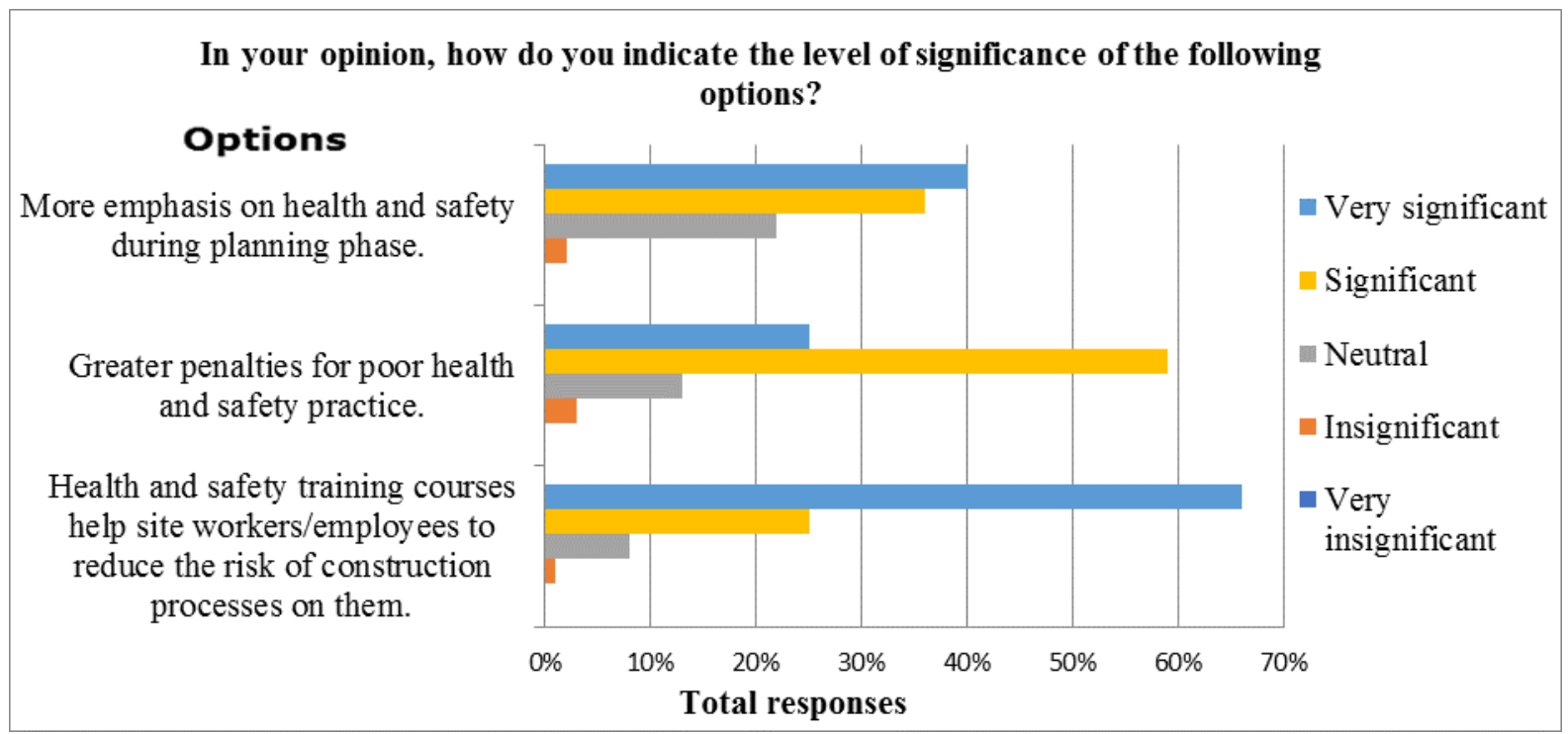

Fig. (15): Respondents' opinions about level of significant of some techniques to reduce risk on H\&S

\subsection{CONCLUSIONS}

The construction industry has a high number of fatalities and long-term injuries. This is unacceptable in a modern society and it also makes the industry inefficient. The results from questionnaire emphasized that construction projects still pose great risks to the H\&S of construction teams, because most of the respondents encountered weekly or monthly $\mathrm{H} \& \mathrm{~S}$ difficulties. Furthermore, fatal accidents occurred regularly in both countries. This research found that the high rates of accidents are due to several common factors such as lack of safety in design, poor construction planning, inadequate safety training, worker behavior, and lack of knowledge of site rules. Also, construction risks may be produced by the lack of awareness of organizations to the $\mathrm{H} \& \mathrm{~S}$ of employees, especially in developing countries like Iraq. The research concluded that by adequate $H \& S$ training courses for employees, more emphasis on H\&S during the project planning phase, and greater penalties for poor $\mathrm{H} \& \mathrm{~S}$ practice, the risk of construction to the lives and wellbeing of workers could be reduced.
In addition, falling from height was the most likely accidents to cause fatal and major injuries to workers in the construction industry. To reduce falling from height, this research suggested protected edges, safe access and secure edge protection and use of appropriate scaffolding with good edge protection. Moreover, worker use of safety belts would protect them from falling and minimize the harms (including fatality) of such accidents if they do occur, including lost working time injuries. Lifting and handling injuries were the most likely accidents to cause lost working time injuries. To reduce lifting and handling injuries, this research suggested using special machines and tools to reduce the quantity of manual handling work by workers. It also suggested using good conditions personal protective equipment by workers according to the types of work they are engaged in, presuming these activities cannot be mechanized.

The results of this study suggested that the organizations should be more take care about $\mathrm{H} \& \mathrm{~S}$ of their construction teams to minimize construction risks to an acceptable value. Companies should prepare employees before starting construction work and provide them with 
relevant information to identify risks to avert risks on their H\&S. Contractors should encourage workers to follow H\&S instructions. Moreover, organizations through worker supervisors can reduce $\mathrm{H} \& \mathrm{~S}$ risks by providing worker supervisors for each team/ group of workers engaged in different places within the same projects, especially in large projects. The worker supervisors should have sufficient experience and knowledge to encourage the workers to carry out their works safely.

\section{REFERENCES}

- AS/NZS (2001) Occupational Health and Safety Management System, Australia, 2001

- Bobick, T. G., Stanevich, R. L., Pizatella, T. J., Keane, P. R. and Smith, D. L. (1994). Preventing falls through skylights and roof opening. Professional Safety, 39, 33-37.

- BS OHSAS (2009), Occupational health and safety management systems - Requirements, BSI Group, '2009

- Cheng, E., Fang, D., Li, H., and Xie, F. (2004). Construction safety management: An exploratory study from China. Construction Innovation, 4, 229-241.

- Creative Research System (CRS) (2015). The Survey System: Survey Design. Retrieved June 8, 2014, from

http://www.surveysystem.com/sdesign.htm.

- Cretu, O., Stewart, R. and Berends, T. (2011). Safety management for Design and Construction. Hoboken, NJ: John Wiley \& Sons.

- Davies, V. and Tomasin, K. (1990). Construction Safety. London: Thomas Telford Ltd.

- Derr, J., Forst, L., Chen, H. Y. and Conroy, L. (2001). Fatal falls in the US construction industry, 1990-1999. Journal of Occupational and Environmental Medicine, 4, 853-860.

- Griffith, A. and Howarth, T. (2001). Construction Health and Safety Management. Edinburgh: Pearson Education.

- Health and Safety Executive (2013b). Work-Related Injuries and Ill Health in Britain. Retrieved August 2014, from http://www.hse.gov.uk/statistics/industry/constr uction/construction.pdf

- Health and Safety Executive (2013c). Work-Related Injuries and Ill Health in Britain. Retrieved August 10, 2014, from http://www.hse.gov.uk/statistics/industry/constr uction/construction.pdf.

- Health and Safety Executive (2014c). Statistics: Construction. Retrieved August 15, 2014, from
http://www.hse.gov.uk/Statistics/industry/constr uction/construction.pdf.

- Howarth, T. and Watson, P. (2009). Construction Safety Management. Chichester, UK: WileyBlackwell.

- Huang, X. and Hinze, J. (2003). Analysis of construction worker fall accidents. Journal of Construction Engineering and Management, 129(3), 262-271.

- Janicak, C. A. (1998). Fall-related death in the construction industry. Journal of Safety Research, 29, 35-42.

- Joyston-Bechal, S., and Grice, H. (2004). Health and Safety Law for the Construction Industry. 2nd edition. London: Thomas Telford.

- Lehto, M. and Salvendy, G. (1991). Models of accident causation and their application: Review and reappraisal. Journal of Engineering and Technology Management, 8(2), 173-205.

- Li, R. and Poon, S. (2013). Construction Safety. Berlin: Springer-Verlag.

- Occupational Health and Safety Management Systems (2012) American National Standards Institute/American Industrial Hygiene Association/American Society of Safety Engineers, 2012

- Occupational Health and Safety Management System (2016). Draft Standard, International Standards Organization, 2016

- Peyton, R. and Rubio, T. (1991). Construction Safety Practices and Principles. New York: Van Nostrand Reinhold.

- Rubio-Romero, J., Carmen Rubio G'amez, M. and Carrillo-Castrillo, J. (2013). Analysis of the safety conditions of scaffolding on construction sites. Safety Science, 55, 160--164.

- Schaufelberger, J. and Lin, K. (2014). Construction Project Safety. Hoboken, New Jersey: John Wiley \& Sons.

- Tam, C., Zeng, S. and Deng, Z. (2004). Identifying elements of poor construction safety management in China. Safety Science, 42(7), 569-586.

- Thorpe, B. (2005). Health and Safety in Construction Design. Aldershot, Hants, England: Gower.

- Twort, A., and Rees, J. (2011). Civil Engineering Project Management. 5th edition. Oxford: Spon Press.

- Zin, S. and Ismail, F. (2012). Employers' behavioural safety compliance factors toward occupational, safety and health improvement in the construction industry. Procedia-Social and Behavioral Sciences, 36, 742-751. 
Journal of University of Duhok, Vol. 20, No.1 (Pure and Eng. Sciences), Pp 546-560, 2017

elSSN: 2521-4861 \& pISSN: $1812-7568$ 